\title{
Detection of the founder effect in Finnish CADASIL families
}

\author{
Kati Mykkänen*,1 , Marja-Liisa Savontaus ${ }^{1}$, Vesa Juvonen ${ }^{1,2}$, Pertti Sistonen ${ }^{3}$, \\ Seppo Tuisku ${ }^{4}$, Susanna Tuominen ${ }^{5}$, Maila Penttinen ${ }^{6}$, Johan Lundkvist ${ }^{7}$, Matti Viitanen ${ }^{8,9}$, \\ Hannu Kalimo ${ }^{10,11,12}$ and Minna Pöyhönen ${ }^{13}$
}

\begin{abstract}
${ }^{1}$ Department of Medical Genetics, University of Turku, Turku, Finland; ${ }^{2}$ Department of Clinical Chemistry, Turku University Hospital, Turku, Finland; ${ }^{3}$ Finnish Red Cross Blood Transfusion Service, Helsinki, Finland; ${ }^{4}$ Department of Neurology, Keski-Pohjanmaa Central Hospital, Kokkola, Finland; ${ }^{5}$ Department of Neurology, Turku University Hospital, Turku, Finland; ${ }^{6}$ Clinical Genetics Unit, Turku University Hospital, Turku, Finland; ${ }^{7}$ Department of Cell and Molecular Biology, Karolinska Institutet, Stockholm, Sweden; ${ }^{8}$ Division of Geriatric Medicine, Karolinska Institutet, Stockholm, Sweden; ${ }^{9}$ Department of Geriatric Medicine, University of Turku, Turku, Finland; ${ }^{10}$ Department of Pathology, Turku University Hospital, Turku, Finland; ${ }^{11}$ Department of Pathology, Uppsala University, Uppsala, Sweden; ${ }^{12}$ Department of Pathology, Helsinki University and University Hospital, Helsinki, Finland; ${ }^{13}$ Department of Medical Genetics, The Family Federation of Finland, Helsinki, Finland
\end{abstract}

Cerebral autosomal dominant arteriopathy with subcortical infarcts and leukoencephalopathy (CADASIL) is an inherited cerebrovascular disease characterized by brain infarcts, cognitive decline and dementia. The disease is caused by at least $\mathbf{9 1}$ missense mutations, four deletions and one splice site mutation in the NOTCH3 gene, which maps to 19p13.1. In 18 out of the 21 Finnish CADASIL families so far identified, the causative mutation is an arginine to cysteine substitution in position 133 (R133C). Most of the families carrying this mutation originate from the western coast of Finland, thus suggesting a founder effect. No previous reports of a founder effect in CADASIL have been published. We haplotyped 60 patients from these $\mathbf{1 8}$ families for $\mathbf{1 0}$ microsatellite markers in order to determine whether the families descend from a common ancestor. We found a similar haplotype linked to the mutation in all 18 pedigrees, which indicates a single common ancestor for all the Finnish R133C families. The age analysis of the founder mutation places the introduction of the mutation in the late 1600 s or early 1700 s.

European Journal of Human Genetics (2004) 12, 813-819. doi:10.1038/sj.ejhg.5201221

Keywords: CADASIL; arteriopathy; NOTCH3; founder effect; haplotype

\section{Introduction}

Cerebral autosomal dominant arteriopathy with subcortical infarcts and leukoencephalopathy (CADASIL) is a genetic, progressive, systemic vascular disorder manifesting usually in early adulthood. Early symptoms may include migraine with aura. At the age of 30-50, patients

*Correspondence: Dr K Mykkänen, Department of Medical Genetics, University of Turku, Kiinamyllynkatu 10, FIN-20520 Turku, Finland. Tel: +358 2333 7456; Fax: + 3582333 7300; E-mail: kati.mykkanen@utu.fi Received 20 August 2003; revised 2 March 2004; accepted 16 April 2004 begin to suffer from recurrent transient ischaemic attacks (TIAs) or ischaemic strokes due to subcortical lacunar infarcts. These will eventually lead to a progressive cognitive decline, and finally to a subcortical type of vascular dementia usually beginning after the age of 50 . Patients often also exhibit psychiatric symptoms, for example mood disorders, particularly depression. ${ }^{1-4}$

Vascular abnormalities can be detected by immunohistochemical or electron microscopic analysis before any other signs of CADASIL appear. The arteriopathy is restricted to small and medium sized arteries and it 
primarily affects vascular smooth muscle cells (VSMCs). As the disease progresses, VSMCs degenerate and granular osmiophilic material (GOM) accumulates between VSMCs. GOM is unique to CADASIL, but its origin, identity, or role in the pathogenesis of the disease still remains to be established.

The genetic cause of CADASIL is a mutation in the NOTCH3 gene, which maps to chromosome region 19p13.1. ${ }^{5}$ The NOTCH3 gene encodes a $300 \mathrm{kDa}$ protein that belongs to the evolutionarily conserved Notch receptor family, originally identified in Drosophila melanogaster. Notch receptors are type 1 membrane-spanning proteins that interact with cell-bound ligands, called Delta and Jagged, expressed at the surface of adjacent cells. ${ }^{6}$ In mammals, four Notch receptors (Notch 1-4) and five Notch ligands (Delta-like-1, -3, -4, Jagged-1, -2) have been described. An increasing body of evidence suggests that ligand-induced Notch signalling plays a pivotal role, both in various developmental contexts during embryonic development and also in adult tissues. ${ }^{6}$ However, the specific role of Notch3 signalling in different developmental paradigms remains unclear. In adult human tissues, the expression of NOTCH3 is restricted to the arterial VSMCs. ${ }^{7}$ It appears that, in CADASIL, the extracellular domain (EC) of Notch3 accumulates on the cell membrane of the VSMCs in close vicinity to deposits of GOM. ${ }^{7}$ Whether the accumulation Notch3 EC domain per se leads to a pathogenic effect in the VSMCs remains to be elucidated.

The NOTCH3 gene consists of 33 exons that encode a protein of 2321 amino acids. Notch3 has a large EC domain, in which the main structural motif is a repeat of 34 epidermal-growth-factor-like (EGF-like) domains. Each EGF-like domain contains six conserved cysteine residues, $^{3}$ which are vital for the correct folding of the EGF-like repeats and possibly for the function of the receptor. $^{6}$ All CADASIL-causing mutations identified so far are located in the EGF-like domains of NOTCH3. ${ }^{6,8-10}$ At present, there are at least 96 mutations known to cause CADASIL, ${ }^{2,11-16}$ of which 91 are missense point mutations. The other mutations consist of four deletions ${ }^{2,17}$ and one splice site mutation. ${ }^{18}$ The mutations result in an odd number of cysteine residues in the target EGF-like repeat. Either one cysteine residue is replaced with another amino acid, or vice versa, or in the case of deletions, one or three cysteines are deleted. So far, two patients homozygous for a pathogenic NOTCH3 mutation have been characterized. ${ }^{17,19}$ In addition, two Japanese patients have been reported as carrying a noncysteine mutation. ${ }^{20,21}$

CADASIL is found worldwide and in many ethnic groups. The number of patients is growing with the increasing knowledge of the disease, yet CADASIL is thought to be markedly underdiagnosed. In Finland, 21 CADASIL pedigrees have been diagnosed so far, with a total of 87 patients, in whom the diagnosis has been confirmed with a mutation analysis $(n=85)$ or a skin biopsy $(n=2)$. In 18 of these families, the cause of the disease is the C475T missense mutation in exon 3 of the NOTCH3 gene, which results in the R133C substitution targeting the EGF4 domain. One family carries the R182C mutation, while in the remaining two families the causative mutation is yet to be determined. Most of the pedigrees carrying the R133C mutation (10/18) originate from Mid Ostrobothnia on the western coast of Finland (Figure 1). Two smaller clusters are located in Northern Savo-Karelia in Eastern Finland (6/18), and Satakunta in western Finland (2/18) (Figure 1). The overrepresentation of a single mutation and the geographic clustering of the families indicate at least one founder effect among the Finnish CADASIL families. We conducted a haplotype analysis of all 18 pedigrees carrying the R133C mutation in order to determine if the patients share a common haplotype around the mutation, which would indicate a possible founder effect. Furthermore, using the linkage disequilibrium (LD) information derived from the haplotype data, we also aimed to estimate the age of the founder mutation.

\section{Material and methods}

For haplotype analysis, 10 polymorphic microsatellite markers flanking the NOTCH3 gene were selected (Figure 2). D19S221, D19S840, D19S415 and D19S929 are located telomeric of the NOTCH3 gene, while D19S411,

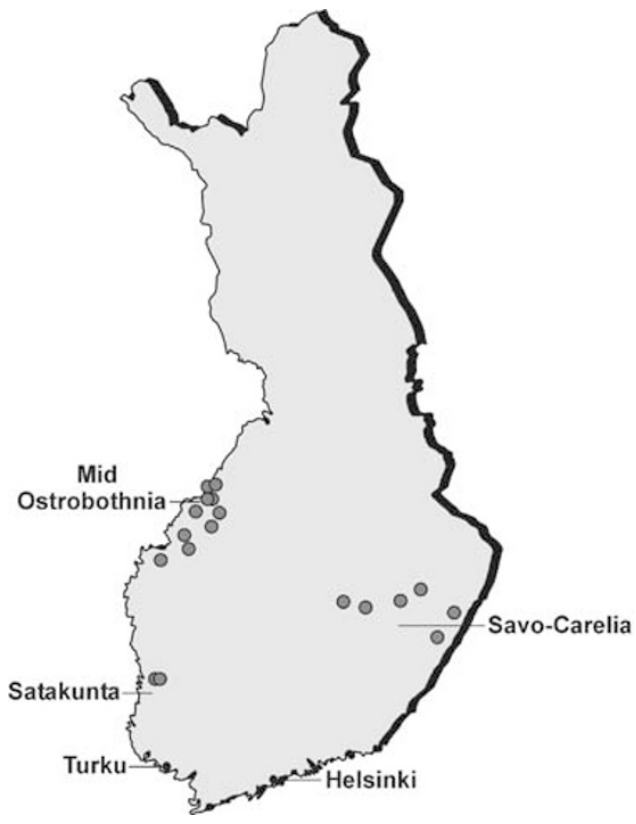

Figure 1 Geographical clustering of the Finnish CADASIL families carrying the R133C mutation. The origin of the oldest known patient in each family, according to church records, is marked on the map. 


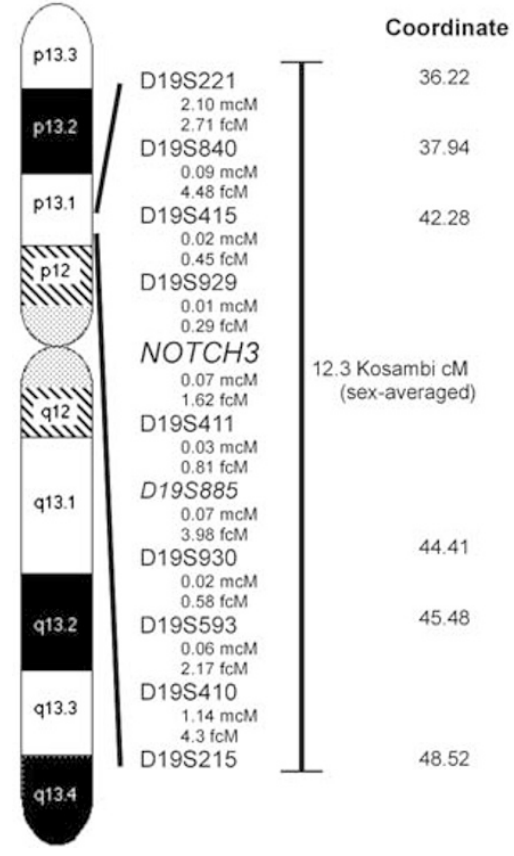

Figure 2 The order and genetic distances of the markers used. Genetic distances for females (fcM) and males (mcM) separately are given according to GDB (http://gdb.org/). Sex-averaged genetic distances (KCM) were obtained from Marshfield sex-averaged genetic map for chromosome 19.

D19S885, D19S930, D19S593, D19S410 and D19S215 are centromeric. All of the selected markers are dinucleotide repeat sequences, except for D19S593, which is a tetranucleotide repeat. The analysis was started with the six markers nearest to NOTCH3 and then extended by four additional markers as the variation among the first haplotypes appeared suboptimal for the purpose of estimating the age of the mutation. Together, the markers used in the analysis cover a DNA region of 12.3 Kosambi cM (KcM, sex-averaged). The order of the markers and genetic distances between them were obtained from the Genetic Location Database (LDB) (http://cedar.genetics.soton. ac.uk/public_html/19smap/smap.html) and Marshfield sex-averaged genetic map (http://research.marshfieldclinic.org/genetics/). Map information and the distances of the markers are illustrated in Figure 2. All information on primer sequences, allele distributions and allele sizes of the markers was obtained from the Genome Data Base (GDB) (http://gdb.org/).

A total of 60 patients from 18 Finnish CADASIL families $(\mathrm{A}-\mathrm{R})$ were haplotyped. From the families $\mathrm{F}, \mathrm{K}$ and $\mathrm{R}$, only one patient each was available for the study. From family P, only the homozygous patient (individual P1) was included. ${ }^{19}$ Allele frequencies of CADASIL patients were compared with those of the Finnish population by using patients' nondisease chromosomes, the alleles of the patients' spouses and siblings analysed and also 50 Finnish control chromosomes genotyped.

Leukocyte DNA was extracted from EDTA blood. The microsatellite regions were amplified with a radioactively labelled standard PCR procedure with 30 cycles and a reaction volume of $25 \mu \mathrm{l}$.

The lengths of the microsatellite repeats were determined with denaturing PAGE in $6 \%$ gels with the M13 DNA sequencing ladder. The haplotypes linked to CADASIL were inferred by the allele segregation in each family.

To estimate the age of the Finnish R133C mutation, we utilized the program DMLE $+{ }^{22,23}$ (version 2.14) that uses a Bayesian inference with the Markov chain Monte Carlo (MCMC) method to obtain mutation age from LD data (from haplotypes or genotypes). The program was given the following parameters: (1) The location of the NOTCH3 locus within the haplotype, $\theta=0.06$. (2) An estimated population growth parameter $\lambda$, with $\lambda=0.14$ elected as the final value based partly on the history of the Finnish population and census data. The program was tested for sensitivity to variation in this demographic parameter also with values 0.10 and 0.20 . (3) For the proportion of the R133C chromosomes in our sample of all the R133C carriers in the Finnish population, a final value of 0.12 was used (assuming the real number of carriers that would be included with our criteria is about 200 in Finland) given the dominant mode of inheritance and assuming underdiagnosis. The sensitivity to this parameter was also tested using values $0.05,0.10$ and 0.20 . In each of the above settings, either one of the parameters was kept at its final value and an identical seed was used for the pseudorandom number generator. We performed 10 million iterations to obtain good convergence of the posterior probability frequency distribution. As all the microsatellite markers were within nongenic regions, uniform priors were used. The data consisted of 24 disease chromosomes and 48 control haplotypes, of which 12 and 28 were complete, respectively. The control haplotypes were obtained from the patients' nondisease chromosomes and the haplotypes of the spouses and noncarrier siblings were analysed. Each haplotype was included only once from any one family. The families were traced back by church records up to 10 generations in some cases and many of them coalesced during the process. Thus, related nuclear families in these large pedigrees were considered independent, and the inclusion criterion for haplotypes was at least six meiotic events separating the haplotypes.

\section{Results}

The marker allele frequencies in the control chromosomes and in the patient haplotypes are shown in Table 1. For the allele frequencies, only the confirmed genotypes have been 


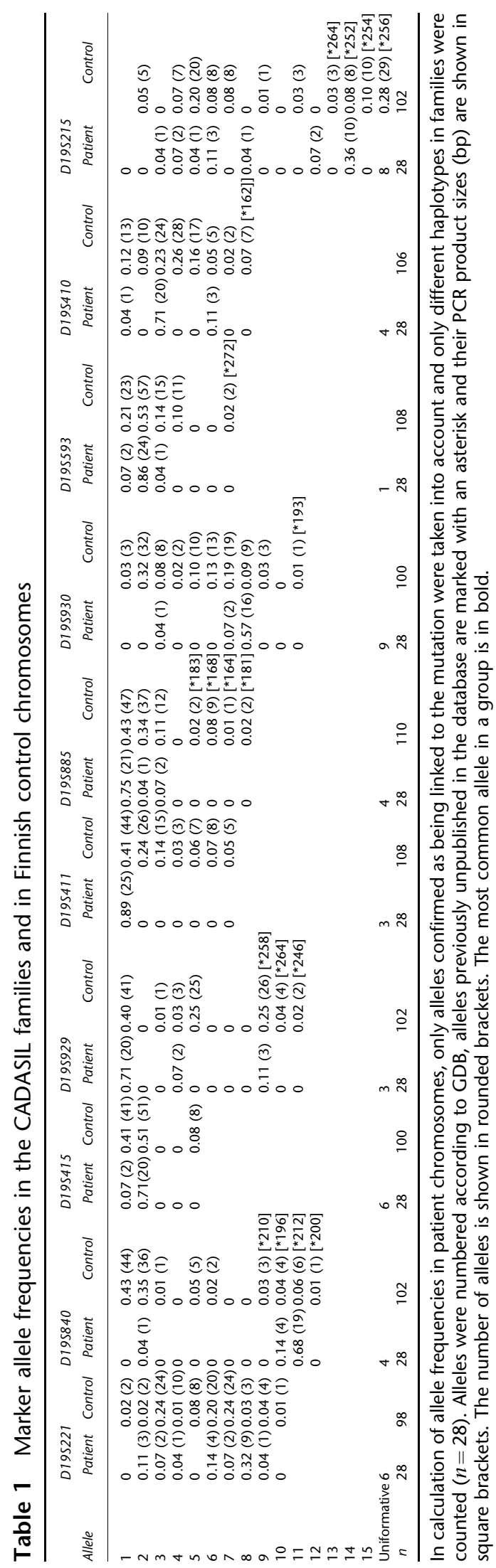

included. We found 18 alleles unpublished in the database (GDB) for seven markers from the Finnish population. The new alleles and their allele sizes are given in Table 1.

The haplotypes of the patients studied are illustrated in Table 2. Most of the families shared a similar marker allele set linked to the NOTCH3 C475T/R133C mutation (Table 2, shaded areas).

In all 18 families, patients had allele 1 for marker D19S411 next to the NOTCH3 gene, except for patient Q6. Three families (A-C) shared a similar haplotype throughout the region studied. Eight families (A, B, D, E, I, J) and one patient from family $\mathrm{N}(\mathrm{N} 1)$ had an identical haplotype for markers D19S415 to D19S885. In total, 10 families (A-H, J, $\mathrm{K})$ and one patient (N1) shared a similar haplotype through D19S840 to D19S593. A total of 15 families (A-O) had a similar haplotype for markers D19S415, D19S929 and D19S411. The most common haplotype in families for all markers was 8-11-2-1-1-1-8-2-3-14.

For individuals F1, K1 and R1, no samples from relatives were available for analysis. For these families, the alleles flanking the mutation could not be determined, except in cases where the patient was homozygous for the marker allele. In addition, in other families, some alleles linked to the mutation could not be determined due to the uninformativity for that marker in the family. In most of the uninformative cases the consensus haplotype is still possible and even likely, since the alleles of the common haplotype were present in these patients' genotypes (Table 2, light shaded areas).

In the haplotypes of families I, O, Q, R and in patients 2-8 from family $\mathrm{N}$, there are some differences from the common CADASIL haplotype. It is our belief that these haplotypes still express the same founder effect, and the differences can be explained by recombinations or an insertion/deletion of a single repeat in the marker allele. For example, the three different alleles in the middle of the consensus haplotype of family $\mathrm{O}$ could result from a single recombination event between markers D19S411 and D19S885 with a haplotype carrying alleles 3 and 14 at the two last markers, or, though more unlikely, from two recombination events in the same meiosis in the past. On the other hand, for marker D19S929, the difference between allele 9 ( $258 \mathrm{bp})$ in the haplotype of family Q and allele 1 (256 bp) of the consensus haplotype is only one repeat, and therefore the difference is most likely due to an insertion of a repeat in one meiosis during the history of this family.

The age analysis of the founder mutation using the most likely parameters resulted in a maximum at 12.2 generations (Figure 3, graph B). The changes of the parameters for population growth (Figure 3, graphs A-C) did not result in a prominent change in results, and neither did those for the proportion of $\mathrm{R} 133 \mathrm{C}$ chromosomes in our sample (Figure 3, graphs D-F). Therefore, if the generation span is considered to be 25 years, the mutation would date back to the late 1600 s or the beginning of the 1700 s. 
Table 2 Haplotypes linked to the R133C mutation in 18 Finnish CADASIL families

\begin{tabular}{|c|c|c|c|c|c|c|c|c|c|c|c|}
\hline Locus & $D 19 S 221$ & D19S840 & D19S415 & D19S929 & Notcle 3 & D19S411 & DI9S885 & D19S930 & D19S593 & D19S410 & $D 19 S 215$ \\
\hline Patient & $1.72 \mathrm{Kct}$ & $\mathrm{CM} \quad 4.34 \mathrm{KCM}$ & $M \quad 0.00 \mathrm{Kct}$ & $\mathrm{M} \quad 0.00 \mathrm{Kal}$ & A $\quad 0.00 \mathrm{KcM}$ & M $\quad 0.00 \mathrm{KcM}$ & H $\quad 2.13 \mathrm{Kcl}$ & $M \quad 1.07 \mathrm{Kch}$ & $M \quad 0.00 \mathrm{KcA}$ & $M \quad 3.04 \mathrm{Kcl}$ & \\
\hline$A 1-5$ & 8 & II & 2 & $I$ & $R 133 C$ & I & $I$ & 8 & 2 & 3 & 14 \\
\hline$B t-5$ & 8 & II & 2 & 1 & $R / 33 C$ & I & 1 & 8 & 2 & 3 & 14 \\
\hline B 6.7 & 4 & II & 2 & 1 & RI33C & 1 & 1 & 8 & 2 & 3 & 14 \\
\hline$C l-3$ & 8 & II & $2 / 1$ & 1 & RI33C & I & 1 & 8 & 2 & $3 / 4$ & 14 \\
\hline$D i-2$ & 8 & II & 2 & I & RI33C & $I$ & 1 & 8 & 2 & 3 & 8 \\
\hline D 3.4 & 8 & II & 2 & 1 & $R / 33 C$ & 1 & 1 & $s$ & 2 & 3 & 4 \\
\hline$E:-2$ & 6 & II & 2 & 1 & R133C & 1 & 1 & 8 & 2 & 3 & $4 / 6$ \\
\hline$F !$ & $8 / 4$ & $11 / 12$ & $2 / 1$ & $1 / 9$ & RI $33 C$ & 1 & 1 & $2 / 8$ & 2 & $3 / 1$ & $4 / 6$ \\
\hline$G i-2$ & $8 / 7$ & $11 / 2$ & $2 / 1$ & 1 & $R / 33 C$ & $1 / 2$ & $1 / 3$ & 18 & 2 & $3 / 5$ & $12 / 16$ \\
\hline$H i-2$ & $\delta$ & II & 2 & 1 & R133C & $1 / 2$ & $1 / 3$ & 28 & $1 / 2$ & 3 & $3 / 15$ \\
\hline 11 & $7 / 6$ & 11 & 2 & 1 & R133C & $I$ & 1 & 28 & 1 & 3 & 14 \\
\hline 12 & $8 / 3$ & HI & 2 & 1 & RI33C & 1 & 1 & 28 & 1 & 3 & $8 / 15$ \\
\hline$J i-2$ & 8 & II & 2 & 1 & RI33C & 1 & 1 & $2 / 8$ & 2 & 3 & 12 \\
\hline$J 3$ & 3 & II & 2 & $i$ & R133C & $t$ & $i$ & $2 / 8$ & 2 & 3 & 12 \\
\hline$K i$ & $8 / 7$ & $11 / 2$ & 211 & $1 / 9$ & RI33C & 1 & $1 / 3$ & 8 & 2 & 23 & $1 / 12$ \\
\hline 2.1 .4 & 7 & 10 & 2 & 1 & RI33C & I & 1 & 8 & 2 & 3 & 14 \\
\hline LS & 7 & 10 & 2 & 1 & $R 133 C$ & 1 & 1 & 8 & 2 & 6 & 6 \\
\hline$M:-3$ & 3 & 10 & 2 & 1 & R133C & $I$ & 1 & 8 & 2 & 3 & 6 \\
\hline$N I$ & 2 & II & 2 & i & RI33C & 1 & 1 & 8 & 2 & 3 & 1012 \\
\hline$N 2-6$ & 2 & II & 2 & 1 & RI33C & 1 & 3 & $s$ & 2 & 6 & 5 \\
\hline$N 7-8$ & 2 & II & 2 & 1 & RI33C & 1 & 3 & 8 & 2 & 6 & 4 \\
\hline oit & 9 & II & $2 / 1$ & I & RI33C & I & 2 & 3 & 3 & 3 & 14 \\
\hline$P I^{*}$ & 8 & 10 and 2 & 1 & 4 & $R / 33 C$ & 1 & 1 & 8 & 2 & 3 & 3 and 6 \\
\hline$Q i$ & 6 & 11 & 2 & 9 & RI33C & 1 & 1 & $2 / 3$ & 2 & 3 & $3 / 6$ \\
\hline$Q 2-5$ & 6 & II & 2 & 9 & $R 133 \mathrm{C}$ & 1 & 1 & 7 & 2 & 3 & 14 \\
\hline Q6 & 6 & II & 2 & 9 & R133C & $2 / 7$ & 1 & 7 & 2 & 3 & 14 \\
\hline RI & $7 / 3$ & $11 / 2$ & - & $1 / 5$ & R133C & $I$ & $1 / 2$ & $2 / 7$ & 2 & $I$ & If \\
\hline
\end{tabular}

Families are indicated with letters (A-R) and patients by numerical order. All different haplotypes in each family are given. Alleles with an unknown phase are separated with a slash. Identical haplotypes shared by the patients are marked with dark grey. Possible unconfirmed similarities are marked with light grey. The patient homozygous for R133C is marked with an asterisk. Sex-averaged genetic distances of the markers are shown in the top row.

\section{Discussion}

Finnish CADASIL families carrying the Notch3 R133C mutation share a similar haplotype, linked to the mutated NOTCH3 gene. The region of the strongest LD includes markers D19S840, D19S415, D19S929, D19S411, D19S885 and D19S930, and spans 6.47 KcM (Table 2, families A-K, $\mathrm{N})$. The consensus haplotype shared by families indicates a common ancestor and a single founder effect among the families carrying the pathogenic R133C mutation. The most common haplotype in the families for all markers, 811-2-1-1-1-8-2-3-14, represents the founder haplotype inherited from a common ancestor. The Finnish founder effect is the first one to be reported in CADASIL.

The relatively long region of consensus haplotype shared by families suggests a fairly young founder mutation. A survey on the genealogy of our CADASIL families reaches back as far as 10 generations without a common ancestor, and therefore confirms that the mutation event must be older. The results of the mutation age analysis indicate that the ancestral R133C mutation is most likely over 12 generations old (Figure 3, graph B), which indicates that the introduction of the mutation to the Finnish population would have happened in the late 1600 s or early 1700 s. In the light of our present knowledge, an actual mutation event cannot be discriminated from its possible immigration from elsewhere outside of Finland.
In 1523-1560 the ruler of Sweden and Finland, King Gustavus Vasa, favoured the settling of unpopulated hunting grounds in Finland for enlarging the kingdom's territory and increasing its tax income. Encouraged by the favourable taxation of settlers and the pressure to cultivate more land for the growing population, from the mid-1500s through the 1600s people from Southern Savo region migrated. At first these people moved mainly to eastern, central and northern parts of Finland, ${ }^{24}$ but others continued onwards to sparsely populated villages in MidOstrobothnia, and some even as far as to Sweden and Norway (Virrankoski P, personal communication). This internal migration movement offers a possible explanation for the clustering of the CADASIL families in Eastern and Western Finland. The mutation would have originated in Savo-Karelia and then migrated to the western coast. Migration of the mutation in the opposite direction is also possible but more unlikely in the light of the Finnish population history and our age analysis.

In Finland, due to the population history there are founder effects in many genetic disorders, ${ }^{25}$ for example in lysinuric protein intolerance $(\mathrm{LPI})^{26}$ and aspartylglucosaminuria (AGU). ${ }^{27}$ Furthermore, the study of Finnish, Swedish and Norwegian patients with Kennedy disease (spinal-bulbar muscular atrophy, SBMA) revealed a Fenno-Scandinavian founder effect. ${ }^{28}$ The C475T/R133C substitution is a relatively common pathogenic mutation of the NOTCH3 gene and it 

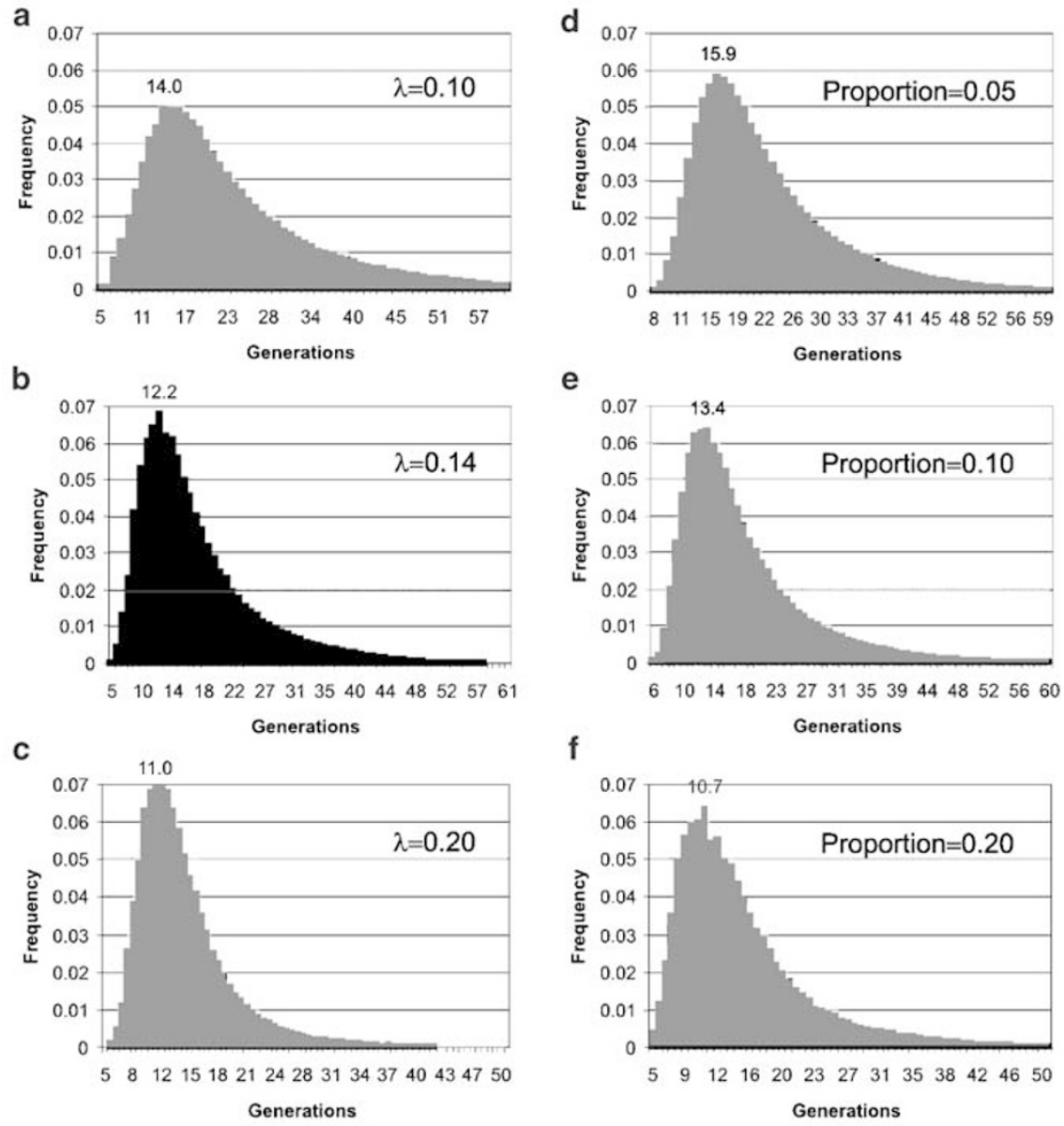

Figure 3 Age estimation of the R133C founder mutation. Posterior frequency distribution of the Finnish CADASIL R133C mutation by program DMLE +, using haplotypes consisting of 10 microsatellite markers in 24 chromosomes of the Finnish CADASIL families and 48 respective control chromosomes. In total, 10 million iterations have been requested after a $10 \%$ burn in run. The iterations were distributed in 100 bins shown as outline of columns in the figure. In each graph, the generation at which the highest frequency was reached is indicated. Graph B was obtained by using the most likely parameter estimates, lambda 0.14 and proportion 0.12 . The graphs with lambda $(\mathbf{a}-\mathbf{c})$ are all computed assuming the proportion 0.12 is true. The graphs with proportion $(\mathbf{d}-\mathbf{f})$ indicate the proportion of the number of the chromosomes in the sample from those assumed present in the Finnish population (each with lambda set to 0.14 ). The $95 \%$ credible intervals in the graph order were 40.44 , $27.86,17.66,32.14,28.21$ and 25.86 generations, respectively.

has been found in at least seven other populations, ${ }^{9,12,29-32}$ including Sweden and Denmark. The geographical locations of the clusters and the fact that the migration of people of Southern Savo has reached as far as Sweden and Norway, encourages us to search for haplotype resemblance among Finland's western neighbours. Our future goal is to study Scandinavian CADASIL patients with the R133C mutation, and possibly patients from other populations as well, to determine the full extent of the founder effect.

\section{Acknowledgements}

We are grateful to the patients and their families for participating in this study. We thank all the clinicians, who took a part in our study.
We also wish to thank Maaria Kleemola and Damon Tringham for their valuable contribution and Mari Peltola for practical assistance. This work was supported by grants from The Academy of Finland, Sigrid Juselius Foundation and the Special Federal Grant of Turku University Central Hospital.

\section{References}

1 Tournier-Lasserve E, Iba-Zizen MT, Romero N, Bousser MG: Autosomal dominant syndrome with stroke-like episodes and leukoencephalopathy. Stroke 1991; 22: 1297-1302.

2 Kalimo H, Ruchoux M-M, Viitanen M, Kalaria RN: CADASIL: a common form of hereditary arteriopathy causing brain infarcts and dementia. Brain Pathol 2002; 12: 371-384.

3 Chabriat H, Vahedi K, Iba-Zizen MT et al: Clinical spectrum of CADASIL: a study of 7 families. Lancet 1995; 346: 934-939. 
4 Dichgans M, Mayer M, Uttner I et al: The phenotypic spectrum of CADASIL: clinical findings in 102 cases. Ann Neurol 1998; 44: 731-739.

5 Joutel A, Corpechot C, Ducros A et al: Notch3 mutations in CADASIL, hereditary adult-onset condition causing stroke and dementia. Nature 1996; 383: 707-710.

6 Artavanis-Tsakonas S, Matsuno K, Fortini M: Notch signalling. Science 1995; 268: 225-232.

7 Joutel A, Andreux F, Gaulis S et al: The ectodomain of the Notch3 receptor accumulates within the cerebrovasculature of CADASIL patients. J Clin Invest 2000; 105: 597-605.

8 Desmond DW, Moroney JT, Lynch T et al: CADASIL in a North American family; clinical, pathologic and radiologic findings. Neurology 1998; 51: 844-849.

9 Joutel A, Vahedi $\mathrm{K}$, Corpechot $\mathrm{C}$ et al: Strong clustering and stereotyped nature of Notch3 mutations in CADASIL patients. Lancet 1997; 350: 1511-1515.

10 Mellies JK, Bäumer T, Müller JA et al : SPECT study of a German CADASIL family: a phenotype with migraine and progressive dementia only. Neurology 1998; 50: 1715-1721.

11 Grigg R, Lea R, Sullivan AA, Curtain R, MacMillian J, Griffiths L: Identification of a novel mutation $\mathrm{C} 144 \mathrm{~F}$ in the Notch3 gene in an Australian CADASIL pedigree; Hum Mut Mutation and Polymorphism Report\# 176 (2000) 60: Online.

12 Lesnik Oberstein SAJ: Diagnostic strategies in CADASIL. Neurology 2003; 60: 2019-2020.

13 Simpson M, Ali N, Dong YB et al : Screening of British CADASIL families for NOTCH 3 mutations. J Med Genet 2001; 38 (Suppl 1): S58.

14 Arboleda-Velasquez JF, Lopera F, Lopez E et al: C455R notch3 mutation in a Colombian CADASIL kindred with early onset of stroke. Neurology 2002; 59: 277-279.

15 Azzarelli B, Miravalle L, Olson J, Ghetti B, Biller J, Vidal R: CADASIL: a familial form of cerebrovascular disease leading to dementia. Identification of two new families and a novel mutation. Neurology 2003; 60 (Suppl 1): A368.

16 Moon SY, Kim HY, Seok JI et al: A novel mutation (C67Y) in the NOTCH3 gene in a Korean CADASIL patient. J Korean Med Sci 2003; 18: 141-144.

17 Dotti MT, Bianchi S, De Stefano N et al : Screening for CADASIL mutations in leukoencephalopathies. Neurology 2003; 60 (Suppl 1): A89.

18 Joutel A, Chabriat H, Vahedi K et al: Splice site mutation causing a seven amino acid Notch3 in-frame deletion in CADASIL. Neurology 2000; 54: 1874-1875.
19 Tuominen S, Juvonen V, Amberla K et al: Phenotype of a homozygous CADASIL patient in comparison to 9 age-matched heterozygous patients with the same R133C Notch3 mutation. Stroke 2001; 32: 1767-1774.

20 Kotorii S, Takahashi K, Kamimura Ket al: Mutations of the notch3 gene in non-caucasian patients with suspected CADASIL syndrome. Dement Geriatr Cogn Disord 2001; 12: 185-193.

21 Uchino M, Hirano T, Uyama E, Hashimoto Y: Cerebral autosomal dominant arteriopathy with subcortical infarcts and leukoencephalopathy (CADASIL) and CADASIL-like disorders in Japan. Ann NY Acad Sci 2002; 977: 273-278.

22 Rannala B, Reeve JP: High-resolution multipoint linkagedisequilibrium mapping in the context of a human genome sequence. Am J Hum Genet 2001; 69: 159-178.

23 Reeve JP, Rannala B: DMLE+: Bayesian linkage disequilibrium gene mapping. Bioinformatics 2002; 18: 894-895.

24 Norio R: Finnish Disease Heritage I: characteristics, causes, background. Hum Genet 2003; 112: 441-456.

25 de la Chapelle A, Wright FA: Linkage disequilibrium mapping in isolated populations: the example of Finland revisited. Proc Natl Acad Sci USA 1998; 95: 12416-12423.

26 Lauteala T, Mykkanen J, Sperandeo MP et al: Genetic homogeneity of lysinuric protein intolerance. Eur J Hum Genet 1998; 6: 612-615.

27 Syvanen AC, Ikonen E, Manninen $\mathrm{T}$ et al : Convenient and quantitative determination of the frequency of a mutant allele using solid-phase minisequencing: application to aspartylglucosaminuria in Finland. Genomics 1992; 12: 590-595.

28 Lund $\mathrm{A}$, Udd B, Juvonen $\mathrm{V}$ et al : Founder effect in spinal and bulbar muscular atrophy (SBMA) in Scandinavia. Eur J Hum Genet 2000; 8: 631-636.

29 Chawda SJ, De Lange RPJ, Hourihan MD, Halpin SFS, St Clair D Diagnosing CADASIL using MRI: evidence from families with known mutations of Notch3 gene. Neuroradiology 2000; 42: 249-255.

30 Uyama E, Tokunaga M, Suenaga A et al: Arg133Cys mutation of Notch3 in two unrelated Japanese families with CADASIL. Intern Med 2000; 39: 732-737.

31 Dichgans M, Ludwig H, Müller-Höcker J, Messerschmidt A, Gasser Thomas: Small in-frame deletions and missense mutations in CADASIL: 3D models predict misfolding of Notch3 EGF-like repeat domains. Eur J Hum Gen 2000; 8: 280-285.

32 Binzer MN, Brattstrom L, Ottosen P, Videbaek H, Stenager E: Clinical, radiological, histopathological and genetic findings in a Danish 'CADASIL' family. Ugeskr Laeger 2000; 162: 1739-1742. 